\title{
Moving Beyond Equal Access: Detracking a High School's Mathematics Program
}

\author{
Lolita A. Tabron ${ }^{1}$, Richard Kitchen ${ }^{2 *}$, Brianna Mestas ${ }^{3}$ \\ ${ }^{1}$ Department of Educational Leadership and Policy Studies, University of Denver, USA \\ 2 School of Teacher Education, University of Wyoming, USA \\ ${ }^{3}$ Department of Teaching and Learning Sciences, University of Denver, USA
}

Received 3 May $2021 \cdot$ Accepted 27 July 2021

\begin{abstract}
Students of color in the United States have historically been denied access to a collegepreparatory mathematics education largely due to tracking policies and practices. To address this historical injustice, a partnership was developed between a highly diverse high school and higher education to initiate a collaborative process to detrack the mathematics program at the school. We report the results from empathy interviews conducted with the "Franklin High" administrative team and mathematics teachers. The four primary themes that emerged from the interviews concerned the school's student diversity, the focus on preparing students to enter the IB course sequence, how detracking must go beyond simply providing equal access, and the importance of the Franklin High staff having an equity-oriented growth mindset. These findings accentuate how successful detracking efforts require stakeholders to have an historical understanding of the racist policies and practices that have led to segregated schools and tracked classrooms.
\end{abstract}

Keywords: design thinking, detracking mathematics, diversity and equity in mathematics

\section{INTRODUCTION}

Success in college-preparatory coursework is one of the most significant factors in college admission decisions and postsecondary enrollment (Battey, 2013). Yet, in pre-tertiary mathematics classrooms in the United States, students of color ${ }^{1}$ continue to be denied access to a college-preparatory mathematics education due to tracking policies and practices, availability of Advanced Placement courses (i.e., honors courses), and low academic expectations embedded in teacher and counselor referrals (Battey, 2013; Patrick et al., 2020). Tracking, also known as ability grouping, places students into groups or classes based on perceived academic ability and is particularly common in the United States in secondary education (Burris \& Garrity, 2008; Oakes, 2005). Tracking communicates to students the racist ideology that "only some people - particularly White, middle-class people-can be good at mathematics" (Boaler, 2011, p. 7). College preparatory mathematics classes are continually viewed as a privilege reserved for White students and measured by white norms, values, and a false ideology of meritocracy (Battey, 2013; Joseph et al., 2016).

Because of tracking, students of color have racially stratified opportunities to learn mathematics (e.g., Patrick et al., 2020). However, there is a shortage of literature that provides practical insights about how to strategically detrack a high school's mathematics curriculum at a school-wide level. In this study, we share our initial research findings from work we have engaged in as "design-thinking improvers." We share our process for how we collaborated to understand and instigate successful heterogeneous grouping of mathematics classes, also known as detracking, at a highly diverse, urban high school in the United States. Detracking involves the removal of the practice of within-school segregation established through curricular tracks such as "honors," "regular" or "remedial" based on perceived ability or aspiration (Chambers, 2009). In close partnership with administrators and teachers at "Franklin High," we initiated an in-depth study of the

1 "Students of color" is a commonly used phrase in the United States and refers to people who are members of racially minoritized groups such as Latinos/as (or simply Latinx), African Americans, Asian Americans, and Native Americans.

(c) 2021 by the authors; licensee Modestum. This article is an open access article distributed under the terms and conditions of the Creative Commons Attribution License (http://creativecommons.org/licenses/by/4.0/).

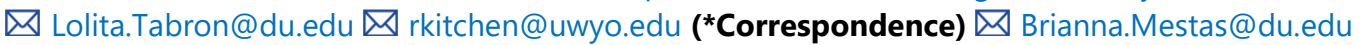




\section{Contribution to the literature}

- Findings from this study provide practical insights that accentuate how successful detracking efforts require stakeholders to have an historical understanding of the racist policies and practices that have led to segregated schools and tracked classrooms.

progression of detracking at the school. We conducted empathy interviews to understand how we might provide all students, regardless of their background or previous mathematics achievement, access to the International Baccalaureate (IB) mathematics program. Our guiding questions were: What could be learned from Franklin High's administrators and mathematics teachers about their perceptions about detracking the mathematics course sequence at the school? How could these perceptions inform the process to detrack the mathematics courses at Franklin High to be equitable and sustainable?

In this paper, we build on the insights of previous research in two ways. First, we provide practical insights into the politics and praxis of detracking in significant ways that help illuminate areas of resistance, sensemaking, capacity, and constituency building for other scholars and practitioners interested in pursuing detracking. Second, we share valuable lessons learned that reveal the complexity of improvement work that design teams should consider and plan for to enhance the sustainability of their school improvement initiatives. In the next section, we share research literature that continues to illustrate the larger structural and institutional factors that result in unequal access to and preparation for high-quality mathematics courses that disproportionately affect students of color in the United States (Leonard, 2018).

\section{The Failure to Educate Students of Color in Mathematics}

Today's public-school enrollment in the United States reflects patterns of growing diversity and ongoing demographic shifts across the nation (Frankenberg et al., 2019). Despite the assets (Ladson Billings, 2006), diverse funds of knowledge (Paris \& Alim, 2014) and community cultural wealth (Yosso, 2006) that students arrive to school with, public education in the United States has historically failed students of color (Milner, 2013), particularly in mathematics education (Aronson \& Laughter, 2016; Leonard et al., 2010; Leonard \& Martin 2013). The practice of tracking students creates conditions in which not all students receive equitable access to rigorous, culturally responsive mathematical content and instruction. Tracking also perpetuates inequitable outcomes impacting postsecondary and career opportunities (Boaler, 2011). While mathematical reasoning through problem solving is a focal point of the mathematics education reform movement in the United States (e.g., National Council of Teachers of Mathematics
[NCTM] 2000, 2014), rigorous mathematics instruction is not often an option at schools attended mainly by historically marginalized students such as Black, Latinx, and Indigenous students. These students have not historically had opportunities to study mathematics with teachers who have the content and pedagogical expertise needed to support the development of their mathematical reasoning through problem solving (Kitchen et al., 2007; Leonard \& Martin, 2013; Martin, 2013). Students of color face systemic barriers of access while also having to contend with deficit stereotypes about their ability to thrive in advanced mathematics courses (Stanley \& Chambers, 2018).

Historically marginalized students commonly experience rote-learning in mathematics classrooms. In schools that serve large numbers of Latinx students, educators may assume their students cannot move beyond rote-learning and engage in mathematical discourse because they are bilingual learners, may speak with an accent, represent various levels of proficiency in English, and express themselves in Spanish (CeledónPattichis \& Ramirez, 2012; Gutiérrez, 2008). Schools that enroll large numbers of Black students in the United States often have disproportionately high numbers of remedial mathematics classes in which instruction is generally focused on rote-learning and strategies that are intended to help students succeed on standardized tests (Davis \& Martin, 2008). In such classrooms, teachers tend to make the memorization of math facts, algorithms, vocabulary, and procedures the focal point of their instruction rather than teaching students through complex, challenging problems (Kitchen et al., 2007). The overreliance on standardized assessments to inform instruction, shed light on school improvement efforts, and evaluate students is problematic as it "assumes a meritocratic academic structure--that all students receive the same access to academic content, instructional design, and pedagogy," which is not the reality for many students of color (Cobb \& Russell, 2015, p. 633). When scores from standardized assessments are situated within political and cultural contexts, it becomes clearer that racial disparities in mathematics achievement are less about a student's ability and more about the academic opportunities that schools provide (Cobb \& Russell, 2015).

\section{Theoretical Framework: Sociopolitical Theoretical Perspective}

In this study, we employed a sociopolitical theoretical perspective. A sociopolitical lens affords a concentrated 
examination of structural inequities and injustices in education in general, as well as specific classroom-level arrangements that may limit students' opportunities to learn at high levels (Kitchen, 2003). A sociopolitical lens places the social, cultural, and political context of learning in the vanguard when examining phenomena such as how tracking affects the learning of mathematics (Boaler, 2011), whether underserved students have access to a standards-based mathematics curriculum (Kitchen et al., 2016), and how race and class influence mathematics instruction (Martin, 2013; Gutiérrez, 2008). In this orientation, educational policies and practices are considered from the perspective that differential access to economic and educational opportunities are rooted in differences based on racialized and classed experiences (Battey, 2013).

\section{METHOD}

\section{Design Thinking}

Design Thinking (DT) is an iterative school improvement methodology that helps bridge the gap between research and practice by developing close partnerships between practitioners and communities to solve complex problems of practice (Minthrop, 2016). Using DT, a partnership developed between Franklin High personnel (administrators and teachers) and researchers from higher education (the first two authors of this article) worked as design-thinking improvers with the common goal of detracking mathematics classrooms at the school. As designers, we believed: (a) In honoring and being in community with and not researching the community, (b) School communities have vast funds of knowledge and strengths to solve problems, (c) Those in the school community are researchers with us in generating solutions to complex problems of practice grounded in social justice.

A distinct feature of the DT process from traditional approaches is that hypotheses are not developed a priori, tested and primarily controlled by academics (Minthrop, 2016). The logic and aim of the work are quite different. In DT, researchers are not engaging with a school district to address their research questions. In this project, the first two authors worked collaboratively with the Franklin High school community as design team members to co-construct a working theory of action that led to school improvement. Our goal was to make significant improvements by expanding access to advanced mathematics coursework for all students at Franklin High. Through leveraging the expertise of both researchers, practitioners, and the Franklin High School community, information and resources were shared to increase efficiency and probability of sustainable success.

The focus of this paper is on the results of one of the strategies used in the first stage of the DT process, the
Discovery phase. We engaged in this phase with Franklin High administrators and mathematics teachers in the fall of 2018. Discovery is an essential stage of the design thinking process. It is used to deeply understand the problem and the system that produces it from the perspective of the users. For our design team, the Discovery phase was intended to help identify what kind of content and administrative support (i.e., professional development, coaching, etc.) the teachers and administrators would need to help students transition from non-IB mathematics courses to all IB mathematics courses. The Discovery phase began with an examination the school's unified improvement plan (UIP) and aim statement that specified the need to have more students prepared for new graduation requirements intended to improve student readiness to take postsecondary mathematics courses without remediation. Specifically, the aim measure was to increase the percentage of $9^{\text {th }}$ and $10^{\text {th }}$ graders from $36 \%$ to $50 \%$ who were meeting grade-level benchmarks and were on track for IB coursework their junior year. A force field analysis revealed that a unified understanding of language, rigor, and expectations was not apparent among the mathematics teachers at Franklin High. This lack of a unified understanding resulted in inequitable access to and preparation for IB mathematics courses among Franklin High students beginning in $9^{\text {th }}$ grade. The design team needed an in-depth understanding of why there was not consistency in rigor, language, and expectations across the mathematics courses offered at Franklin High.

To initiate the Discovery phase, members of the design team identified strategies that could be pursued to support understanding detracking practices at Franklin High from the perspectives of the users. These strategies included listening tours, document analysis, literature reviews, student surveys, peer-to-peer observations, classroom observations by researchers, and semi-structured interviews. In this paper, we present findings from empathy interviews conducted with Franklin High administrators and mathematics teachers. These findings do not reflect a complete design thinking cycle, but represent a small component of the work within the Discovery phase. The empathy interviews were intended to help identify what kind of content and administrative support (e.g., professional development, coaching, capacity building) the teachers and administrators needed as they worked with students to transition them from remedial and non-IB mathematics courses to IB mathematics courses. In the empathy interviews, we employed research strategies used in narrative inquiry (Hamilton et al., 2008). In this approach, we draw on stories told by Franklin High teachers and administrators to examine underlying meanings expressed through narratives (Riessman, 2007). 
Table 1. Information about study participants

\begin{tabular}{lllll}
\hline Pseudonym & Gender Identity & Race & Role & Years at Franklin High \\
\hline Ms. Parker & Female & White & Principal & 3 Years \\
Courtney & Female & White & Math Teacher & 2 Years \\
John & Male & White & Math Teacher Team Lead & 3 Years \\
Cole & Male & White & Math Teacher & 2 Years \\
Dennis & Male & White & Math Teacher & 2 Years \\
Elizabeth & Female & Latina & Math Teacher & 1 Year \\
Anthony & Male & African American & Assistant Principal & 3 Years \\
Samuel & Male & White & IB Coordinator & 2 Years \\
\hline
\end{tabular}

\section{Participants}

The participants in this study were administrators and teachers at Franklin High, a highly diverse high school in a large, urban school district that opened its doors to its inaugural class of $9^{\text {th }}$ graders in the fall of 2015 and has since added a new class of $9^{\text {th }}$ graders annually. The class of 2020 included 168 students, 45\% qualified for the free and reduced-price lunch program. Forty-one percent of the class of 2020 identified as Latinx, $28 \%$ as White, $22 \%$ as Black, $2 \%$ as Asian, and $7 \%$ as "multiple races." 2 Franklin High is part of an open enrollment school district, which means that parents can choose to send their child to any school in the district of their choice, even if the school is not located in their immediate neighborhood. Franklin High is one of the newest and fastest-growing IB Programmes in the state. The school has an open admission policy for its IB Programme and made detracking classes, including mathematics classes, among its top priorities. Detracking included the elimination of remedial, lower track classes and honors mathematics courses. These tracks were removed even if students decided not to choose the IB Diploma or IB Certificate. During the school's first year of existence, there were fierce protests from parents in the community who feared that the school's commitment to detrack would take away student choice, school prestige, and dilute the rigor of the curriculum. These protests, in part, led the school's original principal to resign before the end of the first year of operation.

"Ms. Parker," Franklin High's principal, recognized the ways that curricular tracking, particularly in mathematics, perpetuates racialized outcomes and invited the first two authors to support the school's efforts to detrack their high school mathematics sequence. This invitation provided a unique opportunity to systematically investigate the progression of detracking efforts undertaken at the school. Specifically, detracking at Franklin High had entailed working to have every student at the school enrolled in an IB mathematics course by $11^{\text {th }}$ grade. Ms. Parker already had experience as a principal who had successfully detracked a middle school. She brought her leadership experience to the detracking work at Franklin High. Having an established partnership with a high school committed to and engaged in this detracking effort was critical in conducting this research. In the spring of 2017, the first two authors, researchers in higher education, worked in partnership with teachers and administrators at Franklin High to detrack mathematics classes using Design Thinking. From the outset, the partnership formed between Franklin High school personnel and the first two authors was characterized by our collective commitment to detrack mathematics courses and expand access to advanced mathematics coursework, particularly for historically marginalized students (Patrick et al., 2020).

In addition to Ms. Parker, there were seven others from Franklin High who participated in semi-structured interviews in August 2018. We interviewed five mathematics teachers, Ms. Parker, assistant principal, and IB coordinator. Table 1 provides information about the participants.

\section{Data Collection and Analysis}

The primary purpose of the interviews conducted with the eight participants was to learn about the administrators' and teachers' views on the school culture at Franklin High, their perspectives on equity in mathematics education, and their views regarding every student at their school taking IB courses in mathematics based on the social, cultural, and political contexts of their school community. The interview questions are listed in Appendix A. Each interview lasted between 45 minutes and one hour.

The interviews were analyzed through a sociopolitical lens. Using this lens, we analyzed administrators' and teachers' views vis-à-vis regarding detracking a diverse highly school to understand and instigate detracking of mathematics classes. Using interpretive methods (Creswell \& Poth, 2018), each data subset was read or viewed as a whole, followed by a period of open coding. An iterative process of coding, reflecting upon, and then clarifying administrators' and teachers' views followed (Miles et al., 2013). We reanalyzed each transcript using a constant comparative method until either no new categories were developed or consistency was achieved (Miles et al., 2013).

2 Information retrieved from the Franklin High website. 


\section{Ethical Considerations}

Ethical approval for this school improvement work was granted through school and district sponsorship, approval by the district and university's IRB, and written consent by each interviewee. To maintain anonymity, pseudonyms were used for school district participants.

\section{FINDINGS}

Our findings reflect the perceptions Franklin High teachers and administrators held about detracking to provide unrestricted access to advanced mathematics through the IB Programme to all students regardless of their background or prior academic history in mathematics. Unrestricted access refers to students not having to apply, have parental request, counselor recommendation, or a certain grade to enroll in an IB course. Four themes that emerged from the interviews were: (1) The cultural and linguistic diversity of the school community is a vital asset to detracking, (2) Detracking is best started in the earliest grade, (3) Detracking must transcend equal access, and (4) Equityoriented growth mindsets sustain detracking efforts.

\section{Cultural and Linguistic Diversity of the School Community is a Vital Asset for Detracking}

It was common for Franklin High administrators and mathematics teachers to talk about the diversity and culture of the student population at the school as something that they valued. For example, Courtney, one of the mathematics teachers on the design team, said, "I love the diversity of our school, I think it's beautiful!" Several participants noted how students socialized across racial and ethnic lines, which created a unique culture at the school. John, the high school mathematics team lead, said:

The students are fantastic! We actually have a diverse school, population wise, that interacts with each other and it's not totally separate. You know it's not like all the Black kids hang over here and the Latino kids over there and the White kids over here, they are very intermingled. It's just really nice to be in that environment, it's a big thing obviously with the students. This is huge for me, you know there's the classic schools that are built by the White man, for the White man, and I feel we are doing our work to tear that down.

The school culture that was developing at Franklin High was one in which students not only socialized across ethnic and racial lines, but also worked across ethnic and racial lines. According to Ms. Parker, the school principal:

The first thing I always tell people who don't know anything about Franklin High is the ability of our students to work with students who are not like them, the ability of students to build relationships with kids in the classroom. One of the things that really drove me here was the kids themselves, and how they work together, how they collaborated, how they got along with each other. You didn't have what you have in a lot of other schools. You didn't have pockets of segregation, pockets of you know, this is where all the Black kids go, this is where Latino kids go, this is where White kids go. You don't see that, you see a very strong cohesive community, which is tremendous.

Ms. Parker discussed how detracking at Franklin was also contributing to an inclusive academic culture at the school. In the following quote, she asserted that the student body's diversity was also reflected in the IB classes at the school. In response to a question about how diversity existed across mathematics classes, Ms. Parker said:

I honestly think it's the fact that we don't run a separate honors curriculum. We don't run a separate honors class, we don't run a separate honors track, and because we don't, kids of all you know achievement levels are in class together. They're working together, they're helping each other, you know get through material, and I really believe that is what has led to the culture we have here. The expectation is you will work with anybody within the classroom. There is no separation whatsoever.

According to Ms. Parker, the integrated and cohesive community that had formed at Franklin High was in response to challenges that ensued after the school's first principal left because of community pressure during the school's initial year of existence. An event that could have created a divisive and segregated school culture instead forged strong bonds and reinforced an inclusive and desegregated academic and social school environment. This was viewed as a vital asset in the process of detracking the mathematics courses at Franklin High.

\section{Detracking Should be Initiated in Ninth Grade}

A significant feature of the IB Programme at Franklin High was that it was open to all the school's students, regardless of their past academic achievements. Ms. Parker stated, "That's why we don't do an application for IB either, because we want it open for all kids. So, even if you're a C student or a D student, you still have an opportunity if you want to take that level a little further. We don't want to isolate any kids." A goal at the school was to have students who attended the school enroll in at least two IB classes by their junior year, though students could elect to enroll in the full IB 
Diploma Programme. Preparing students to be ready to enter an academically demanding mathematics course by $11^{\text {th }}$ grade meant taking inventory of the current mathematics offerings.

Prior to the DT partnership and work, Franklin High had already begun to detrack their mathematics classes by eliminating non-IB mathematics courses and aligning the remaining classes to the IB curriculum. Teachers and administrators believed that phasing out the lowest mathematics tracks was the right first step to detracking. They also believed that early success in 9th-grade mathematics courses was essential for teachers' collective efficacy and to build students' confidence for IB mathematics coursework. In addition, the goal existed at Franklin High to intervene with ninth-graders who had negative mathematical identities that could limit them as they moved forward in the mathematics program. Courtney said:

I think at Franklin, one of the biggest things it would take to move students to IB is their success in their freshmen year math... Not just academic success, yes academic but not just their grades, but their perceived confidence in themselves. You know in freshmen year if you end up with a $C$ or $\mathrm{D}$ in freshmen math, you are not gonna believe that you can be an IB student."

Similarly, Ms. Parker talked about how some students at the school had not previously experienced much success in mathematics and needed teachers to motivate and affirm their capacity as mathematicians:

We have kids that have been defeated by math... and you know when you come to high school and not having been successful in math through middle school, or elementary, you know your chances of graduating are pretty slim. Your chances of going to college are, you know, pretty slim, and so, you know getting kids motivated, and having the right teacher to motivate kids, and teaching them that 'yes, you can do this.' You have to persevere you know, that is the key I think to any math class.

The administrators' and teachers' reflections about the initial stages of detracking indicate that students needed to experience successes in mathematics, and these successes needed to begin in the 9th grade mathematics classes. These classes were the first that students took at Franklin High. It was important in these classes to build students' confidence in themselves as mathematicians, reaffirm the inclusive and desegregated academic culture at the school, and provide high-level support early to prepare students for an advanced mathematics curriculum.

\section{Detracking Must Transcend Equal Access}

For Franklin High administrators and teachers, there was a clear commitment to prepare students to enter and be successful in the IB Programme. However, in discussions that took place among design team members about the detracking process, it became clear that a distinction needed to be made between equity and equal opportunity in this process. Courtney shared, "I think Franklin does very well with equality, maybe not as well with equity. That would give all students an equal opportunity, but we sometimes don't work as hard with the students who already started behind and get them up to speed." Courtney went on to say "... tracking students is the easy way to do things. It's a lot easier for differentiation. It's a lot easier for a class to manage. But I think we have people in our team who are open minded and willing to do the hard things for the best outcome for the students."

John, the mathematics team lead, had mixed feelings about the high expectations and pressure to have all students enrolled in the IB Programme. He reflected on how the IB Programme was a topic so frequently discussed with students at the school that it had created anxiety among some students:

I think just the name IB scares a lot of kids, scares a lot of teachers, and then everyone starts thinking that maybe the students wouldn't be able to handle the rigor of this content... So, in order to get every student there, I mean I think we are right there, it's really just a change in mindset of what kids can and cannot handle.

While much attention was paid at Franklin High to establishing strong academic goals for students in mathematics, many teachers expressed concern that students were not well-prepared to move into higher level mathematics courses. Cole, another mathematics teachers on the design team, told us, "I think it's a very nice goal. I think it's a good goal to try to get everyone in IB. But, mathematically, statistically, it's an impossibility, at least in my mind... There's only so much time we can respond to the needs of freshmen who come in 2-3 or more grade-levels behind." This reflection indicates that not only do historically marginalized students have to fight for access to advanced mathematics classes, but students must also fight against deficit thinking. Deficit thinking "is grounded in the belief that culturally different students are genetically and culturally inferior to White students" (Ford, 2010, p. 32). This deficit thinking is grounded in racist ideology that can be traced back to eugenics (Tabron \& Chambers, 2019). Deficit thinking about students' perceived academic ability has been used to justify tracking and the ideology that some students are disinterested in advanced mathematics, not able to catch up, or simply 
not 'college material' (Cobb \& Russell, 2015; Tabron \& Chambers, 2019).

Providing access to advanced mathematics by eliminating low-track courses, labels, grade requirements, and teacher recommendation processes is a significant first step towards equal access to advanced mathematics. However, equal access does not address the systemic inequities experienced by marginalized students of color and students from low-income households (Domina et al., 2016; Rothstein, 2017).

\section{Equity-Oriented Growth Mindsets Sustain Detracking Efforts}

Franklin High teachers and administrators frequently spoke about the importance of everyone involved in the detracking work possessing a growth mindset. The emphasis on growth mindsets at the school was necessary to promote and sustain successful detracking efforts, while challenging deficit-based belief systems that sustain tracking. Ms. Parker stated:

I think the right teachers to support our students are first and foremost teachers who have a growth mindset for all kids, who don't believe in fixed ability, fixed achievement levels, that very much believe that if we set the bar high and provide kids support that they'll meet our expectations.

John also discussed the need for teachers to be open to improve their instruction and embrace a growth mindset about their own practices. John said:

The right teachers here are the ones who don't think they know it all, they don't have this notion of how I've done it for 20 years, and this is how I am gonna continue to do it. They are very open to change, they are very open to feedback and they act on that feedback because they know they are not the best teachers in the world. They're eager to grow themselves, they're eager to grow the students and reflect on themselves as well.

These responses demonstrate the importance that Ms. Parker and John placed on having a core group of teachers and administrators who believed in detracking and were invested in doing the hard work to meet their students' needs. These are teachers and administrators who embraced reforming inequitable academic practices and were open to learning about and implementing alternative teaching methodologies. Detracking is not about fixing students, but about being willing "to grow themselves" as teachers to meet the culturally and linguistically diverse needs of their students. Following Ms. Parker's lead, much value was placed at Franklin High on students accessing and excelling in advanced mathematics. There was also agreement that students who were behind in mathematics needed supplementary academic support in $9^{\text {th }}$ grade. Some
Franklin High mathematics teachers were willing to do this work. For instance, Courtney said, "Our team is willing to do what is right by putting students in a position to succeed."

While there was much attention paid at Franklin High on establishing strong academic goals for students in mathematics and providing them with the academic support they needed to meet these goals, many teachers expressed concern that students were not always well prepared to move into higher level mathematics courses. This indicates a need to provide mathematics teachers at Franklin High with professional development to promote an equity-oriented growth mindset to help teachers critically interrogate assumptions and beliefs about students and their ability to succeed in advanced mathematics.

\section{DISCUSSION}

In this study, a sociopolitical theoretical perspective was employed to address two research questions that focused on (1) learning about the perceptions that Franklin High's administrators and mathematics teachers held about detracking the mathematics course sequence at the school, and (2) examining these perceptions to move detracking forward to be equitable and sustainable. Embedding the detracking work within a sociopolitical framework lent a critical interpretation of the underrepresentation of historically marginalized youth in advanced mathematics courses (Boaler, 2011) at Franklin High. Rather than attributing the racial disparities in mathematics access and achievement to student failures or ignoring the presence of racist and gendered structures and norms (Oakes, 2005; Rothstein, 2017), our use of a sociopolitical lens helped expose the structures that constrained students' opportunities and resulted in students being inadequately prepared for advanced mathematics courses (Battey, 2013). In this study, the sociopolitical lens was also helpful for understanding the inclusive learning culture that had developed at Franklin High and the value placed on teachers having equity-oriented growth mindsets as a key building block for detracking the mathematics courses at the school. Moreover, this lens helped uncover tensions that existed among Franklin High administrators and teachers about detracking; while some teachers were devoted to preparing their students for the rigors of IB coursework by their junior year, doubts existed among other teachers about whether students could actually be adequately prepared for IB coursework. Lastly, the sociopolitical framework was helpful for gaining insights about how detracking must go beyond simply providing equal access for students to advanced coursework in mathematics.

Considering the first research question, we learned that administrators and the mathematics teachers believed that the cultural and linguistic diversity of the 
school community was a vital asset for detracking. Universal enthusiasm existed about the school's rich student diversity and the inclusive learning culture that was emerging at the school. Notably, Ms. Parker and some of the school's teachers attributed this inclusive culture to the fact that the original $9^{\text {th }}$ grade cohort weathered a challenging situation when the school's original principal resigned during the school's first year because of the politics surrounding detracking. Rather than creating a divisive and segregated school culture, the event helped forge strong bonds among students and reinforced an inclusive and desegregated academic and social school environment. The administrator and teacher narratives also point to the significance placed at the school on implementing intentional strategies and policies that could promote positive relationships among students and the community. Student advisement and desegregating courses were among the strategies used at Franklin High to help students develop authentic social and academic relationships with their peers.

The reflections from the administrators and teachers about the initial stages of detracking also illustrate the importance placed at Franklin High on students experiencing success in mathematics. These successes needed to begin in the 9th grade mathematics classes. There was also a persistent focus on preparing students to enter the IB mathematics course sequence by their junior year through detracking, which primarily entailed eliminating mathematics courses that would not prepare students for the rigors of an IB mathematics course. Tremendous energy was devoted at Franklin High to address potential gaps in students' mathematics preparation during their first two years at the school to prepare them to enter an IB course by their junior year. Based on the teachers' narratives, it was also clear that tensions had emerged regarding the practicality of preparing every student at the school to be prepared to enter an IB mathematics course after only two years. While all teachers wanted to support students' success in mathematics, some questioned the viability of detracking the entire mathematics program given the divergent mindsets, perspectives, and levels of buy-in among the mathematics teachers regarding detracking.

With regards to the second research question, there was a shared understanding among some of Franklin High's mathematics teachers about historical injustices caused by tracking (Oakes et al., 1997). Courtney told us: "We shouldn't be punishing students because of their race or SES." She also talked about "tearing down" racist policies and practices that have historically led to segregated schools and tracked classrooms. However, not all of the mathematics teachers shared Courtney's historical understanding of why detracking was needed. Undertaking detracking at Franklin High was challenging. It required finding teachers who believed that detracking mathematics courses was essential to provide equity and access to advanced mathematics for all students who were willing to do the work to make this happen. However, some of the teachers' narratives about access to the IB Programme indicated more of a commitment to equality rather than to equity. Specifically, some teachers expressed doubt that it was realistic to believe that every student could succeed in IB courses by their junior year. Some of the teachers' responses also demonstrated teacher compliance vis-àvis detracking at the school rather than authentic buy-in to the school's detracking policies. Helping teachers understand and critically interrogate their beliefs is an integral part of the detracking process. It is important to have honest and transparent conversations early and continuously during the detracking process because these beliefs will inform praxis and relationships between teachers and the students (Burris \& Garrity, 2008).

To build capacity at Franklin High to engage in detracking policies and practices in mathematics, the school needed "the right teachers," with an equityoriented growth mindset who understood the school's vision and were willing to do the work to realize it. Teachers and administrators at Franklin High spoke about the need to have teachers at the school who set a high bar for students, while providing students with needed academic support to meet high expectations (Kitchen et al., 2007). There was also broad agreement that the best teachers are the ones who are open to improving for the sake of their students' learning (Boaler, 2016). To support teachers to develop an equityoriented growth mindset, professional development could focus on supporting teachers to critically interrogate their assumptions and beliefs about students and their abilities to be successful in advanced mathematics.

\section{IMPLICATIONS FOR PRACTICE}

Data from the interviews and other data collected during the Discovery phase were collectively reviewed by the design team to inform Interpretation, the second step in the DT process. From the findings from this Discovery phase, our design team offer the following recommendations for practitioners and design teams engaged in detracking at their schools.

\section{A Need for Community Engagement}

As partners with Franklin High, we found that while there were school-wide expectations for detracking and an expressed value for community voice and engagement, there was limited community engagement in the school's detracking work. This lack of engagement was a direct consequence of the damage done at the school during its first year when Franklin High's principal left after intense parental protest to detracking. Given the school's commitment to being an IB 
Programme School, perhaps in retrospect the protests to detracking could have been expected since many parents most likely associate IB with tracking; only the best students, their children, should be in a more academically demanding program such as an IB program. Whatever the reason, the legacy of the protests appears to be trepidation on the behalf of the Franklin High administration to engage the school community in the detracking work that is underway. This apprehension is certainly understandable, given the crisis that the school experienced in its first year. Hopefully, though, a concerted effort can be made in the future to engage the school community in the important work of detracking at Franklin High by engaging community representatives on the design team. It is important to do this to cultivate community support and legitimacy to the detracking work being done as well as to heal past wounds.

\section{Culturally Responsive Professional Development}

To critically interrogate beliefs about tracking and detracking requires a historic understanding of systemic inequities in the United States that have created educational inequities for historically marginalized students, particularly in STEM (Leonard, 2018). Successful detracking efforts require the commitment of all members of the design team (administrators, teachers, staff, students, community members, and researchers) to become effective culturally responsive educators. It requires educators who are committed to cultivating critical consciousness and academic achievement within themselves and youth (Fickel et al., 2017). As highlighted in the findings section, the right teachers to support detracking are equity-minded educators who have a growth mindset both in relation to student achievement and their teaching practices. Whereas most mathematics teachers at Franklin High had positive perceptions of student diversity and were able to critically analyze and articulate the negative impact of tracking practices, some expressed deficitbased beliefs about students. This misalignment in values, beliefs, and expectations of students within the mathematics department indicates a need for teachers to engage in individual and group work around culturally responsive values and teaching practices. In the case of Franklin High, an intensive series of ongoing professional development learning opportunities around culturally responsive mathematics teaching (CRMT) is one practical intervention that could be implemented. Aguirre \& Zavala (2013) conceptualize CRMT as "a set of specific pedagogical knowledge, dispositions, and practices that privilege mathematical thinking, cultural and linguistic funds of knowledge, and issues of power and social justice in mathematics education" (p. 163).

There are several potential positive outcomes to an ongoing departmental-wide focus on CRMT. First, the department would have a common set of learning experiences and language to ground their work. Second, teachers would gain tools to grow their sociopolitical development (Zion et al., 2015) to critically reflect upon the intersection of their beliefs and actions in their individual and collective practice. Third, teachers would learn how to operationalize culturally responsive beliefs and practices (Aronson \& Laughter, 2016) in mathematics education. Most importantly, teachers would improve their pedagogies to support the mathematical learning of their culturally and linguistically diverse students (Aguirre \& Zavala, 2013).

\section{Detracking Should Include Teacher Assignments}

There is a need for the more experienced mathematics teachers to teach the 9th grade courses instead of assigning novice teachers to teach these courses. Similar to what is happening nationally, the more experienced mathematics teachers at Franklin taught the more advanced courses (Kalogrides et al., 2011). Novice teachers were assigned to teach the more challenging classes that were populated by students who were often 2-3 years behind in mathematics. The disparity in teacher assignments is usually attributed to principals wanting to retain the more experienced teachers and can also be attributed to power relations within schools that benefit more experienced teachers (Kalogrides et al., 2011). Placing novice teachers in less-challenging classrooms would help them gain experience and persist and potentially stay longer in the teaching profession (Kapadia \& Coca, 2007).

\section{Engage Students as Active Partners and Decision- Makers}

Although student voices were engaged through student surveys as part of the Discovery phase, it was a passive attempt to engage student voices. While students were at the heart of Franklin High administrators' and mathematics teacher's decisionmaking and agenda, Franklin High youth were not viewed or engaged as key decision-makers. An important recommendation, then, is to engage youth as active partners and decision-makers because such engagement is a positive catalyst in school improvement and reform efforts (Bertrand, 2018; Keisu \& Ahlström, 2020; Mauldin, 2019). Developing a more reciprocal relationship means including youth as members of the design team through participatory methodologies (Duren, 2020) or redesigning the organizational leadership structure to officially include youth. This is critical as Mauldin (2019) asserted, "Youth of color are experts of their schooling experiences and can provide insider perspectives related to inequity in schools - their voices deserve to be central to how school leaders engage in decision making in the K-12 school setting" (p. 27). Youth offer a unique vantage point from their first-hand lived experiences with inequity and can name 
inequitable practices and reimagine practices and processes that could promote their success with perhaps greater precision than any other stakeholder.

\section{LIMITATIONS}

Since Franklin High community members and students were not part of the design team, insights derived from the empathy interviews were limited. Furthermore, since new mathematics teachers have joined the staff at Franklin High since the original empathy interviews were conducted in August 2018, there is a need to interview the new teachers to learn about their perceptions about detracking to help continue inform the detracking process at the school.

\section{CONCLUSION}

While detracking efforts will vary by context, design teams involved in detracking in the United States and wherever such practices need to be reformed should critically examine the systems that perpetuate inequitable outcomes. They will also need to interrogate the beliefs and ideologies held by key stakeholders, such as teachers, coordinators, and administrators (Bryke et al., 2015). After all, individuals and systems work in tandem to create teaching and learning environments, and both must be critically interrogated when they are producing inequities among students. Ultimately, despite the complexities of the work, there must be a shared and deep-rooted commitment to detracking in mathematics as a matter of social and racial justice in education.

Author contributions: All authors have sufficiently contributed to the study, and agreed with the results and conclusions.

Funding: No funding source is reported for this study.

Declaration of interest: No conflict of interest is declared by authors.

\section{REFERENCES}

Aguirre, J., \& Zavala, M. (2013). Making culturally responsive mathematics teaching explicit: A lesson analysis tool. Pedagogies: An International Journal, 8(2), 163-190. https://doi.org/10.1080/1554480X. 2013.768518

Aronson, B., \& Laughter, J. (2016). The theory and practice of culturally relevant education: A synthesis of research across content areas. Review of Educational Research, 86(1), 163-206. http:/ / doi.org/ $10.3102 / 0034654315582066$

Battey, D. (2013). Access to mathematics: A possessive investment in Whiteness. Curriculum Inquiry, 43(3), 332-359. http:/ / doi.org/10.1111/curi.12015

Bertrand, M. (2018). Youth participatory action research and possibilities for students of color in educational leadership. Educational Administration Quarterly,
54(3), 366-395. http:/ / doi.org/10.1177/0013161X18 761344

Boaler, J. (2011). Changing students' lives through the de-tracking of urban mathematics classrooms. Journal of Urban Mathematics Education, 4(1), 7-14. https://doi.org/10.21423/June-v4i1a138

Bryk, A. S., Gomez, L. M., Grunow, A., \& LeMahieu, P. G. (2015). Learning to improve: How America's schools can get better at getting better. Harvard Education Press.

Burris, C. C., \& Garrity, D. T. (2008). Detracking for excellence and equity. Association for Supervision and Curriculum Development.

Celedón-Pattichis, S., \& Ramirez, N. G. (Eds.), (2012). Beyond good teaching: Advancing mathematics education for ELLs. National Council of Teachers of Mathematics.

Chambers, T. V. (2009). The "receivement gap": School tracking policies and the fallacy of the "achievement gap". The Journal of Negro Education, 78(4), 417-431.

Cobb, F., \& Russell, N. M. (2015). Meritocracy or complexity: Problematizing racial disparities in mathematics assessment within the context of curricular structures, practices, and discourse. Journal of Education Policy, 30(5), 631-649. https:/ / doi.org/10.1080/02680939.2014.983551

Creswell, J. W., \& Poth, C. N. (2018). Qualitative inquiry and research design: Choosing among five approaches (4th edition). Sage Publications.

Davis, J., \& Martin, D. B. (2008). Racism, assessment, and instructional practices: Implications for mathematics teachers of African American students. Journal of Urban Mathematics Education, 1(1), 10-34. https://doi.org/10.21423/June-v11i1$2 \mathrm{a} 358$

Domina, T., Hanselman, P., Hwang, N., \& McEachin, A. (2016). Detracking and tracking up: Mathematics course placements in California middle schools, 2003-2013. American Educational Research Journal, 53(4), 1229-1266. http:/ / doi.org/10.3102/00028312 16650405

Duren, R. (2020). Do you hear us? Amplifying alternative pathways for high school pushouts through youth participatory action research [Doctoral Dissertation in Practice, University of Denver]. University of Denver Digital Commons. https://digital commons.du.edu/elps_doctoral/13/

Fickel, L. H., Henderson, C., \& Price, G. (2017). Language, culture and identity at the nexus of professional learning. Educational Research, 59(4), 391-407. https:/ / doi.org/10.1080/00131881.2017.1373029

Ford, D. Y. (2010). Underrepresentation of culturally different students in gifted education: Reflections 
about current problems and recommendations for the future. Gifted Child Today, 33(3), 31-35. https:/ / doi.org/10.1177/107621751003300308

Frankenberg, E., Ee, J., Ayscue, J. B., \& Orfield, G. (2019). Harming our common future: America's segregated schools 65 years after Brown. www.civilrightsproject. ucla.edu

Gutiérrez, R. (2008). A "gap gazing" fetish in mathematics education? Problematizing research on the achievement gap. Journal for Research in Mathematics Education, 39, 357-364. https:// doi.org /10.2307/40539302

Hamilton, M. L., Smith, L., \& Worthington, K. (2008) Fitting the methodology with the research: An exploration of narrative, self-study and autoethnography. Studying Teacher Education, 4(1), 1728. https:/ / doi.org/10.1080/17425960801976321

Joseph, N. M., Haynes, C. M., \& Cobb, F. (Eds.), (2016). Interrogating Whiteness and relinquishing power: White faculty's commitment to racial consciousness in STEM classrooms. Peter Lang Publishing. https: / / doi.org/10.3726/978-1-4539-1716-9

Kalogrides, D., Loeb, S., \& Beteille, T. (2011). Power play? Teacher characteristics and class assignments: (721612011-001) [Data set]. American Psychological Association. https:/ / doi.org/10.1037/e721612011001

Kapadia, K., \& Coca, V. (2007). Keeping new teachers: A first look at the influences of induction in the Chicago Public Schools. Research Report. In Consortium on Chicago School Research. Consortium on Chicago School Research. https://eric.ed.gov/ ?id=ED498332

Keisu, B-I, \& Ahlström, B. (2020). The silent voices: Pupil participation for gender equality and diversity. Educational Research, 62(1), 1-17. https://doi.org/ 10.1080/00131881.2019.1711436

Kitchen, R. S. (2003). Getting real about mathematics education reform in high poverty communities. For the Learning of Mathematics, 23(3), 16-22. https:/ / doi.org/10.2307/40248427

Kitchen, R. S., DePree, J., Celedón-Pattichis, S., \& Brinkerhoff, J. (2007). Mathematics education at highly effective schools that serve the poor: Strategies for change. Lawrence Erlbaum Associates.

Kitchen, R., Anderson Ridder, S., \& Bolz, J. (2016). The legacy continues: "The test" and denying access to a challenging mathematics education for historically marginalized students. Journal of Mathematics Education at Teachers College, 7(1), 17-26. https:/ / doi.org/10.7916/jmetc.v7i1.784

Ladson-Billings, G. (2006). From the achievement gap to the education debt: Understanding achievement in U.S. schools. Educational Researcher, 35(7), 3-12. https:// doi.org/10.3102/0013189X035007003
Leonard, J. (2018). Culturally specific pedagogy in the mathematics classroom: Strategies for teachers and students. Routledge. https://doi.org/10.4324/ 9781351255837

Leonard, J., \& Martin, D. B. (Eds.) (2013). Beyond the numbers and toward new discourse: The brilliance of black children in mathematics. Information Age Publishing.

Leonard, J., Brooks, W., Barnes-Johnson, J., \& Berry, R. Q. (2010). The nuances and complexities of teaching mathematics for cultural relevance and social justice. Journal of Teacher Education, 61(3), 261-270. https:/ / doi.org/10.1177/0022487109359927

Martin, D. B. (2013). Race, racial projects, and mathematics education. Journal for Research in Mathematics Education, 44, 316-333. https:/ / doi.org /10.5951/jresematheduc.44.1.0316

Mauldin, C. (2019). There is no such thing as the voiceless: Positioning youth of color as educational leaders in the elementary school setting. Michigan State University AGEP Science Today Bulletin, 7(1), 26-28. https://grad.msu.edu/sites/default/files/ content/AGEP/2019\%20AGEP\%20Science \% 20To day $\%$ 20Bulletin $\%$ 20Final.pdf\#page $=26$

Miles, M. B., Huberman, A. M., \& Saldaña, J. (2013). Qualitative data analysis: A methods sourcebook. Sage Publications, Inc.

Milner, H. R. (2013). Analyzing poverty, learning, and teaching through a critical race theory lens. Review of Research in Education, 37(1), 1-53. https:/ / doi.org/10.3102/0091732X12459720

Minthrop, R. (2016). Design-based school improvement: A practical guide for education leaders. Harvard Educational Press.

National Council of Teachers of Mathematics. (2000). Principles and standards for school mathematics.

National Council of Teachers of Mathematics. (2014). Principles to actions: Ensuring mathematical success for all.

Oakes, J. (2005). Keeping track: How schools structure inequality (2nd edition). Yale University Press.

Oakes, J., Wells, A. S., Jones, M., \& Datnow, A. (1997). Detracking: The social construction of ability, cultural politics, and resistance to reform. Teachers College Record, 98(3), 482-510.

Paris, D., \& Alim, H. S. (2014). What are we seeking to sustain through culturally sustaining pedagogy? A loving critique forward. Harvard Educational Review, 84(1), 85-100. https://doi.org/10.17763/haer.84.1. 9821873k2ht16m77

Patrick, K., Socol, A. R., \& Morgan, I. (2020). Inequities in advanced coursework: What's driving them and what leaders can do. The Education Trust. 
https:/ / edtrust.org/resource/inequities-inadvanced-coursework/

Riessman, C. K. (2007). Narrative methods for the social sciences. Sage Publications, Inc.

Rothstein, R. (2017). The color of law: A forgotten history of how our government segregated America. Liveright Publishing.

Stanley, D., \& Chambers, T. T. V. (2018). Tracking myself: African American high school students talk about the effects of curricular differentiation. International Journal of Education Policy and Leadership, 13(1), 1-16. http:/ / doi.org/10.22230/ijepl.2018v13n1a748

Tabron, L. A., \& Chambers, T. V. (2019). What is being Black and high achieving going to cost me in your school? Students speak out about their educational experiences through a racial opportunity cost lens. The High School Journal, 103(2), 118-138. https:// doi.org/10.1353/hsj.2019.0002

Yosso, T. J. (2006). Whose culture has capital? A critical race theory discussion of community cultural wealth. Race Ethnicity and Education, 8(1), 69-91. https: / / doi.org/10.1080/1361332052000341006

Zion, S., Allen, C. D., \& Jean, C. (2015). Enacting a critical pedagogy, influencing teachers' sociopolitical development. The Urban Review, 47(5), 914-933. https:/ / doi.org/10.1007/s11256-015-0340-y 


\section{APPENDIX A}

\section{Individual Teacher and Administrator Interview Protocol}

1. What is your motivation for wanting to work at this campus?

2. In the October survey that Franklin High stakeholders completed, one participant stated, "I think we have the right teachers on the team who are dedicated to supporting all students at Franklin." Can you describe who you think the right teachers are to best support Franklin High students?

3. Imagine that you are having a conversation with someone who is unfamiliar with Franklin High and they want to know about students' strengths. What would you tell them are the strengths of the students that you work with?

4. What role, if any, does motivation play in student learning in math?

5. Do you believe that all students have an equal opportunity to achieve at Franklin High?

6. What would it take to move every student into IB coursework in mathematics at the school?

7. Some people would say that tracking is more effective than heterogeneous grouping. What would you say to them?

\section{http://www.ejmste.com}

